\title{
Distribution and virulence properties of extra-intestinal pathogenic Escherichia coli in Turkey
}

\author{
Elif Bozcal \\ Basic and Industrial Microbiology Section, Department of Biology, Faculty of Science, Istanbul \\ University, Turkey
}

\section{Summary}

Extraintestinal pathogenic Escherichia coli (ExPEC) is a universal pathogen which causes variety of diseases that impact on people of all ages. ExPEC strains are genetically diverse and associated virulence factors contribute to the wide spectrum of infections, ranging from urinary tract infections to fatal bacteremia. During the last decade, ExPEC strains have been increasingly reported in Turkey. The development of antibiotic resistance by ExPEC strains, such as extended spectrum beta-lactamase, has important clinical consequences. Studying the distribution and virulence factors of various ExPEC strains will be enhancing our understanding of ExPEC epidemiology and prevalence.

\section{The bad side of the two-faced Escherichia coli: extraintestinal pathogenic $E$. coli}

Escherichia coli is one of the most common Gram negative bacteria of the human gastrointestinal tract (GIT) $(9,36,61)$. Certain $E$. coli strains live in intestine without causing any infection disease (10). However, a small percentage of $E$. coli strains are capable of

Correspondence: Elif Bozcal, Istanbul University, Faculty of Science, Biology Department, Basic and Industrial Microbiology Section, 34134- Fatih, Vezneciler, Istanbul, Turkey.

Tel.: +90.212.4555700.15071.

E-mail: elif.bozcal@istanbul.edu.tr

Key words: Escherichia coli; virulence; Turkey.

Conflict of interest: the author declares no potential conflict of interest.

Received for publication: 1 0ctober 2016.

Revision received: 22 November 2016.

Accepted for publication: 25 November 2016.

(C) Copyright E. Bozcal, 2016

Licensee PAGEPress, Italy

Microbiologia Medica 2016; 31:6324

doi:10.4081/mm.2016.6324

This article is distributed under the terms of the Creative Commons Attribution Noncommercial License (by-nc 4.0) which permits any noncommercial use, distribution, and reproduction in any medium, provided the original author(s) and source are credited. causing various infections outside the GIT. These organisms called Extraintestinal pathogenic Escherichia coli (ExPEC) (45). ExPEC strains generally can be grouped based on infection site and can be divided into four following groups: Uropathogenic $E$. coli (UPEC), neonatal-meningitis causing $E$. coli (NMEC), Avian pathogenic $E$. coli (APEC), and sepsis causing E. coli (SPEC) (46). Among these strains, APEC causes systemic infection in poultry, whereas the other pathogenic ExPEC subsets cause human diseases (29). Even though ExPEC strains are frequently associated with urinary tract infections (UTIs), they are also a major cause of sepsis, meningitis, pneumonia, bacteremia, lower respiratory and skin, soft tissue and central nervous system infections $(17,21,48,49)$. For instance, $E$. coli related to necrotizing fasciitis after renal transplantation was found in a 39year-old male patient in Istanbul(65). ExPEC is also known as collibacillus; in new-borns and adults, it may lead to sepsis and have a mortality rate of approximately $80 \%$ (58). Occasionally, these bacteria are found in the bloodstream, suggesting that these ExPEC strains can remain alive in a non-ferrous environment and are resistant to bactericidal activity present in blood(45).

ExPEC pathogenicity is multifactorial and involves multiple processes, including colonization, host invasion, and bacterial fitness. ExPEC pathogenicity is the result of genes that encode virulence factors (VFs) and are grouped as follows: i) adhesins, ii) toxins, iii) iron acquisition systems, iv) capsule production, and v) protectins and invasins $(22,46)$. Genes for VFs are usually located within pathogenicity islands (PAIs) on plasmids and/or chromosomes.

UTIs associated with ExPEC derived from a fecal reservoir. After urethral colonization, ExPEC strains reach bladder and kidneys where tissue invasion result in serious clinical syndromes. During infection stages, UTIs associated with ExPEC strains use Type I fimbriae to bind uroepithelial cells $(41,60)$. Other VFs important for adhesion are S. fimbriae/F1C fimbriae and P. fimbriae. Furthermore, ExPEC strains acquire ferric iron to grow and then disseminate bloodstream. These processes involve siderophores such as yersiniabactin and aerobactin $(15,26,50)$. To induce uroepithelial injury, ExPEC strains produce toxins such as hemolysin (68). To overcome immune responses, ExPEC strains produce conjugal transfer surface exclusion protein (TraT) which is associated with serum resistance (19). In contrast to UTIs associated with ExPEC, Neonatal meningitis-causing E.coli (NMEC) has particular virulence mechanisms that contribute to invasion of the blood-brain barrier invasion (38). NMEC strains frequently produce a capsule that inhibits phagocytosis. Additionally, bacterial serum resistance is associated with outer membrane proteins (e.g., OmpA) and cytotoxic necrotizing factor 1 (CNF1) is required to develop a high titre bacteremia $(30,53,67)$. With regards to APEC, important VFs are adhesins such as F1 and P fimbriae, K1 capsule and temperature-dependent hemagglutinin (Tsh) (54).

ExPEC strains are distributed throughout the entire world and are 
the most common Gram negative bacteria in humans (63). In Turkey, ExPEC strains is frequently isolated from blood cultures of hospitalized patients $(31,32)$. In 2006, 214,340 blood samples were collected from 43,254 patients in 16 Turkish University hospitals. The most frequent pathogen cultured from these blood samples was identified as E. coli (22.45\%)(3). ExPEC (approximately $28 \%$ of samples) also was detected in Kayseri (63). This ratio increased by $44 \%$ when the blood of patients in the Internal Medicine Department were examined (24). Moreover, ExPEC strains were detected from blood cultures of $34 \%$ of neutropenic patients in Izmir, which is located in western Turkey (74). Furthermore, 55 E. coli strains were detected in total of 10,168 blood cultures from patients reported in Samsun in 2006 (69).

Each year, 1.6 million new-borns die due to the bacterial infections including sepsis. Neonatal sepsis, which is characterized by infection during the first month of life, is responsible for 1 to 8 of these deaths. This rate is much higher in developing countries (64). Sepsis-causing $E$. coli (SPEC) strains are reported frequently in new-borns and generally the main cause of septicaemia $(31,71)$. The source of contamination is usually originates from mother's vagina and rectum microbiota and is designated ExPEC $(4,5)$. Fifty-eight Gram negative bacteria were detected in 6116 blood cultures from the new-born intensive care unit in Kayseri; 21 of these 58 strains were reported as E. coli (36.02\%) (59).A study was performed to determine of demographic characteristics of new-borns diagnosed with late-onset sepsis and to characterize the bacteria. The reported to increase more than three-fold in both SPEC and between 2004 and 2008 (71). Of the 148 patients with bloodstream infections, E.coli was reported as the sepsis-causing agent in 8 of them (5.4\%) at the Neonatal Intensive Care Unit in Diyarbakır, Turkey (39).Further, SPEC was detected in translectal prostate biopsy. Quinolone-resistant $E$. coli was reported in Istanbul in a patient with sepsis; E.coli was presented in the prostate needle biopsy (33).

ExPEC associated with neonatal meningitis (NMEC) has a mortality rate of $40 \%$ (22). Neonatal meningitis is inflammation of meninges that within the first 30 days of life (23). NMEC can lead to neurological disorders including hydrocephalus and encephalopathy (42). ExPEC-related NMEC studies are rare and the ratio of NMEC has not been determined high risk. A study was performed to examine neonatal bacterial meningitis in Turkey the authors studied risk factors and prognosis of NMEC patients between January 2003 and June 2010. Of the118, 091 neonates born in a hospital, 38,023 neonates were hospitalized due to various clinical problems. Among them, 344 patients were diagnosed with meningitis. Regarding these data, maternal risk was evaluated and $E$. coli $(23 \%)$ was reported as most common pathogen (43). Avian pathogenic Escherichia coli (APEC) lead to aerosacculitis, polyserositis, septicaemia and other extraintestinal diseases of many avian species (25). Although, numerous of studies from many locations throughout the world have been reported on APEC, there is no study examining the distribution of APEC in Turkey. ExPEC associated with UTIs are among the most common community-acquired infection all over the world. UTIs are mainly composed of catheter-associated urinary tract infection (CAUTIs), pyelonephritis and simple cystitis (56). Generally, when we examine of the UTIs related to ExPEC strains in Turkey, the reliable detection rate is approximately 70\%. For example, Azap et al. reported that the percentage of UTIs associated E. coli was $57.8 \%$ in Ankara (6). Three years later, Yilmaz et al. stated that most commonly detected bacteria from urine samples was E. coli (68.5\%) in Kars, which is located eastern Turkey (72).This incidence rate was similar with that observed in Izmir, located in the western part of Turkey. In Izmir, UTIs associated with E.coli were detected in 8975 (67\%) of 13,821 urine samples (70). Approximately 15 years ago, 371 of 2083 patients (17.8\%) patients were diagnosed with UTIs out in Samsun (14). During the last 15 years, ExPEC related infections have increased from $17.8 \%$ to $65.3 \%$
(47). ExPEC strains that lead to UTIs generally have Extended Spectrum B-lactamases (ESBLs) resistance. The incidence of community-acquired UTIs due to ESBLs producing $E$. coli has increased worldwide $(37,44,52,62,66)$. One of the most significant ESBL is CTX$\mathrm{M}-15$.The emergence of an intercontinental clone of an $E$. coli strain, producing CTX-M-15 has gained much interest recently $(8,28,57)$. CTX-M-15-producing E. coli strain was reported in 2005 in Turkey and it was first isolated from a hospitalized patient's urine (2). Azap et al. was stated that $6.3 \%$ of $E$. coli isolated form urine samples from patients (aged 18 to 65) who had undergone an operation because of urolithiasis or bladder disservice were ESBL positive (7). Furthermore, for nearly 10 months in Adana, Turkey, the presence of ESBL-positive E.coli was determined in cases of community-acquired UTIs. ESBL-poisitive E.coli was detected in 77 of the 310 (24.8\%) samples (34) (Table 1).

ExPEC strains can be grouped based on clonal variation using multilocus sequence typing (MLST) analysis $(27,51,55)$. With respect to clonal variation, sequence type (ST) 131 strains has drawn much attention in recent years $(1,11,12)$. An $E$. coli ST131 clone, also classified as a ExPEC strain, is significant human pathogen throughout and is known as a pandemic clone, $(16,35)$. Recent studies reported that variety of ST131 clonal groups are associated with antimicrobial resistance profiles including CTX-M-15 type ESBLs. Recently, Johnson et al. described a subclone within ST131, called H30 (40). ST131 comprises approximately 25\% of ExPEC strains in Turkey. Clinical risk factors associated with this subclone within ST131 were studied by Can et al. in Istanbul and the percentage of the $E$. coli that were ST131 was $24.3 \%$ (13). Similarly, Yumuk et al. reported one CTXM-15 producing E. coli ST131 strain in Kocaeli (73). Another study that examine urosepsis pathogenic $E$. coli in the Aegean Region of Turkey reported that 4 of the 30 E. coli strains were ST131 (29).

In conclusion, ExPEC has been reported at high rates in Turkey and this constitutes a major threat to public health. Why ExPEC is significant for the public? It can be explained following reasons; ExPEC has a complicated phylogeny and has a broad range of VFs that conduce to simple urinary tract infections to fatal bacteremia and sepsis $(18,20,22)$. On the other hand, ESBL-producing resistant ExPEC strains are draw attention in recent years. For this reason, actual diagnose strategies are necessary to overcome ExPEC infections. Large scale epidemiological studies are essential to understand transmission dynamics and therapeutic strategies.

Table 1. Distribution of extra-intestinal pathogenic Escherichia coli strains according to the provinces of Turkey.

\begin{tabular}{lccc}
\hline Province & Infection & ExPEC \% & Reference \\
Kars & UTIs & 68.5 & 72 \\
Samsun-1 & UTIs & 65.3 & 47 \\
\hline Samsun-2 & UTIs & 17.8 & 14 \\
İzmir & UTIs & 67.0 & 70 \\
\hline Ankara-1 & UTIs & 57.8 & 6 \\
Ankara-2 & UTIs-ESBL & 6.3 & 7 \\
\hline Istanbul & UTIs-ESBL & 55.1 & 13 \\
Trakya & UTIs-ESBL & 36.7 & 16 \\
\hline Adana & UTIs-ESBL & 24.88 & 33 \\
Kocaeli & UTIs-ESBL & 53.0 & 73 \\
\hline Isparta & UTIs-ESBL & 29.0 & 43 \\
\hline
\end{tabular}

UTIs: Urinary Tract Infections; UTIs- ESBL: Urinary Tract Infection with Extended Spectrum $\beta$ Lactamase. 


\section{References}

1. Accogli M, Giani T, Monaco M, et al. Emergence of Escherichia coli ST131 sub-clone H30 producing VIM-1 and KPC-3 carbapenemases, Italy. J Antimicrob Chemother 2014;69:2293-6.

2. Aktas Z, Gonullu N, Schneider I, et al. Detection of CTX-M-15 type extended spectrum beta-lactamase in an Escherichia coli strain isolated from the urine sample of a hospitalized patient. Mikrobiyoloji bulteni 2005;39:421-9.

3. Altindis M, Koroglu M, Demiray T, et al. A multicenter evaluation of blood culture practices, contamination rates, and the distribution of causative bacteria. Jundishapur J Microbiol 2016;9:1-6.

4. Arısoy ES. Yenido an sepsisi: Tanı ve tedavi yakla ımları. ANKEM Dergisi 2010;24:168-75

5. Aygün G. Sepsis tanısı. Ü Cerrahpa a Tıp Fakültesi Sürekli Tıp E itimi Etkinlikleri. 2006;Sempozyum Dizisi No: 51:51-60.

6. Azap 0, Togan T, Yesilkaya A, et al. Antimicrobial susceptibilities of uropathogen Escherichia coli in renal transplant recipients: dramatic increase in ciprofloxacin resistance. Transplant Proc 2013; 45:956-7.

7. Azap OK, Arslan H, Serefhanoglu K, et al. Risk factors for extended-spectrum beta-lactamase positivity in uropathogenic Escherichia coli isolated from community-acquired urinary tract infections. Clin Microbiol Infect 2010;16:147-51.

8. Bado I, Gutierrez C, Garcia-Fulgueiras V, et al. CTX-M-15 in combination with aac(6')-Ib-cr is the most prevalent mechanism of resistance both in Escherichia coli and Klebsiella pneumoniae, including K. pneumoniae ST258, in an ICU in Uruguay. J Global Antimicrob Resist 2016;6:5-9.

9. Bai L, Schuller S, Whale A, et al. Enteropathogenic Escherichia coli 0125:H6 triggers attaching and effacing lesions on human intestinal biopsy specimens independently of Nck and TccP/TccP2. Infect Immun 2008;76:361-8.

10. Batt RM, Rutgers HC, Sancak AA. Enteric bacteria: friend or foe? J Small Anim Pract 1996;37:261-7.

11. Birgy A, Mariani-Kurkdjian P, Bidet P, et al. Characterization of extended-spectrum-beta-lactamase-producing Escherichia coli strains involved in maternal-fetal colonization: prevalence of E. coli ST131. J Clin Microbiol 2013;51:1727-32.

12. Blanc V, Leflon-Guibout V, Blanco J, et al. Prevalence of day-care centre children (France) with faecal CTX-M-producing Escherichia coli comprising 025b:H4 and 016:H5 ST131 strains. J Antimicrob Chemother 2014;69:1231-7.

13. Can F, Azap OK, Seref C, et al. Emerging Escherichia coli 025b/ST131 clone predicts treatment failure in urinary tract infections. Clin Infect Dis 2015;60:523-7.

14. Canbaz S, Peksen Y, Tevfik Sunter A, et al. Antibiotic prescribing and urinary tract infection. Int J Antimicrob Agents 2002;2):407-11.

15. Caza M, Lepine F, Dozois CM. Secretion, but not overall synthesis, of catecholate siderophores contributes to virulence of extraintestinal pathogenic Escherichia coli. Mol Microbiol 2011;80: 266-82.

16. Cheng MF, Chen WL, Hung WY, et al. Emergence of extended spectrum-beta-lactamase-producing Escherichia coli 025b-ST131: a major community-acquired uropathogen in infants. Pediatr Infect Dis J 2015;34:469-75.

17. Chouikha I, Germon P, Bree A, et al. A selC-associated genomic island of the extraintestinal avian pathogenic Escherichia coli strain BEN2908 is involved in carbohydrate uptake and virulence. J Bacteriol 2006;188:977-87.

18. Chung HC, Lai CH, Lin JN, et al. Bacteremia caused by extendedspectrum-beta-lactamase-producing Escherichia coli sequence type ST131 and non- ST131 clones: comparison of demographic data, clinical features, and mortality. Antimicrob Agents Chemother 2012;56:618-22.

19. Cunha MP, de Oliveira MG, de Oliveira MC, et al. Virulence profiles, phylogenetic background, and antibiotic resistance of Escherichia coli isolated from turkeys with airsacculitis. Sci Wrld J 2014;2014:289024.

20. Dahbi G, Mora A, Mamani R, et al. Molecular epidemiology and virulence of Escherichia coli 016:H5-ST131: comparison with H30 and H30-Rx subclones of 025b:H4-ST131. Int J Med Microbiol 2014;304:1247-57.

21. Dai J, Wang S, Guerlebeck D, et al. Suppression subtractive hybridization identifies an autotransporter adhesin gene of E. coli IMT5155 specifically associated with avian pathogenic Escherichia coli (APEC). BMC Microbiol 2010;10:236.

22. Dale AP, Woodford N. Extra-intestinal pathogenic Escherichia coli (ExPEC): disease, carriage and clones. J Infect 2015;71:615-26.

23. Dale RC, Vincent A. Inflammatory and autoimmune disorders of the nervous system in children. London: Mac Keith Press; 2010.

24. Durmaz S, Kiraz A, Percin D, Do anay M. Antimicrobial resistance profile of Escherichia coli causing bacteremia in patients in intensive care units. Acta Med Mediterran 2015;31:631-3.

25. Ewers C, Li G, Wilking H, et al. Avian pathogenic, uropathogenic, and newborn meningitis-causing Escherichia coli: how closely related are they? Int J Med Microbiol 2007;297:163-76.

26. Fakruddin M, Mazumdar RM, Chowdhury A, Mannan KS. A preliminary study on virulence factors and antimicrobial resistance in extra-intestinal pathogenic Escherichia coli (ExPEC) in Bangladesh. Indian J Med Res 2013;137:988-90.

27. Garcia-Fernandez A, Chiaretto G, Bertini A, et al. Multilocus sequence typing of Incl1 plasmids carrying extended-spectrum beta-lactamases in Escherichia coli and Salmonella of human and animal origin. J Antimicrob Chemoth 2008;61:1229-33.

28. Giedraitiene A, Vitkauskiene A, Pavilonis A, et al. Prevalence of 025b-ST131 clone among Escherichia coli strains producing CTXM-15, CTX-M-14 and CTX-M-92 beta-lactamases. Infect Dis (Lond) 2017;49:106-12.

29. Giray B, Uçar FB, Aydemir SS. Genotypic analysis of Escherichia coli strains that cause urosepsis in the Aegean region. Turk J Med Sci. 2016;46:1-10.

30. Glode MP, Sutton A, Moxon ER, Robbins JB. Pathogenesis of neonatal Escherichia coli meningitis: induction of bacteremia and meningitis in infant rats fed E. coli K1. Infect Immun 1977;16:75-80.

31. Gokalp AS, Oguz A. Neonatal sepsis in Turkey: the comparison between penicillin plus aminoglycoside and ampicillin plus thirdgeneration cephalosporin chemotherapies. J Trop Pediatr 1990; $36: 200$.

32. Gonullu N, Aktas Z, Kayacan CB, et al. Dissemination of CTX-M-15 beta-lactamase genes carried on Inc FI and FII plasmids among clinical isolates of Escherichia coli in a university hospital in Istanbul, Turkey. J Clin Microbiol 2008;46:1110-2.

33. Gözüküçük R, Çakıro lu B, Özaslan H. Sepsis due to quinoloneresistant Escherichia coli after transrectal prostate biopsy. ACU Sa lık Bil Derg 2011;2:107-9.

34. Guran M, Akcimen B, Gokmen T, et al. Characterization of CTX-M type extended spectrum -lactamases of Escherichia coli isolated from urinary tract infections in Southern Turkey: the first report of CTX-M-14 producing Escherichia coli from Turkey. Afr J Microbiol Res 2013;7:551-6.

35. Hernandez J, Bonnedahl J, Eliasson I, et al. Globally disseminated human pathogenic Escherichia coli of 025b-ST131 clone, harbouring blaCTX-M-15 , found in Glaucous-winged gull at remote Commander Islands, Russia. Environ Microbiol Rep 2010;2:329-32.

36. Herrero-Fresno A, Zachariasen C, Hansen MH, et al. Apramycin treatment affects selection and spread of a multidrug-resistant 
Escherichia coli strain able to colonize the human gut in the intestinal microbiota of pigs. Vet Res 2016;47:12.

37. Hickerson $\mathrm{AD}$, Carson CC. The treatment of urinary tract infections and use of ciprofloxacin extended release. Exp Opin Investigat Drugs 2006;15:519-32.

38. Houdouin V, Bonacorsi S, Brahimi N, et al. A uropathogenicity island contributes to the pathogenicity of Escherichia coli strains that cause neonatal meningitis. Infect Immun 2002;70:5865-9.

39. pek M, Özbek E. Bloodstream infections in a neonatal intensive care unit. J Clin Anal Med 2016;7:625-9.

40. Johnson JR. Escherichia coli pathogenicity island-like domains. Infect Immun 2002;70:7185-6.

41. Johnson JR, Kuskowski MA, Gajewski A, et al. Virulence characteristics and phylogenetic background of multidrug-resistant and antimicrobial-susceptible clinical isolates of Escherichia coli from across the United States, 2000-2001. J Infect Dis 2004;190:1739-44.

42. Kaczmarek A, Budzynska A, Gospodarek E. Detection of K1 antigen of Escherichia coli rods isolated from pregnant women and neonates. Folia Microbiol 2014;59:419-22.

43. Kavuncuo lu S, Gürsoy S, Türel Ö, et al. Neonatal bacterial meningitis in Turkey: epidemiology, risk factors, and prognosis. J Infect Devel Countr 2013;7:73-81.

44. Kim YK, Pai H, Lee HJ, et al. Bloodstream infections by extendedspectrum beta-lactamase-producing Escherichia coli and Klebsiella pneumoniae in children: epidemiology and clinical outcome. Antimicrob Agents Chemother 2002;46:1481-91.

45. Koga VL, Tomazetto G, Cyoia PS, et al. Molecular screening of virulence genes in extraintestinal pathogenic Escherichia coli isolated from human blood culture in Brazil. BioMed Res Int 2014;2014:465054.

46. Kohler CD, Dobrindt U. What defines extraintestinal pathogenic Escherichia coli? Int J Med Microbiol 2011;301:642-7.

47. Leblebicioglu H, Esen S, Turkish Nosocomial Urinary Tract Infection Study G. Hospital-acquired urinary tract infections in Turkey: a nationwide multicenter point prevalence study. J Hosp Infect 2003;53:207-10.

48. Lloyd AL, Henderson TA, Vigil PD, Mobley HL. Genomic islands of uropathogenic Escherichia coli contribute to virulence. J Bacteriol 2009;191:3469-81.

49. Lloyd AL, Rasko DA, Mobley HL. Defining genomic islands and uropathogen-specific genes in uropathogenic Escherichia coli. J Bacteriol 2007;189:3532-46.

50. Magistro G, Hoffmann C, Schubert S. The salmochelin receptor IroN itself, but not salmochelin-mediated iron uptake promotes biofilm formation in extraintestinal pathogenic Escherichia coli (ExPEC). Int J Med Microbiol 2015;305:435-45.

51. Manges AR, Harel J, Masson L, et al. Multilocus sequence typing and virulence gene profiles associated with Escherichia coli from human and animal sources. Foodborne Pathog Dis 2015;12:302-10.

52. Moghnieh RA, Musharrafieh UM, Husni RN, et al. E. coli, K. pneumoniae and K. oxytoca community-acquired infections susceptibility to cephalosporins and other antimicrobials in Lebanon. J Med Liban 2014;62:107-12.

53. Mulder CJ, van Alphen L, Zanen HC. Neonatal meningitis caused by Escherichia coli in the Netherlands. J Infect Dis 1984;150:935-40.

54 Nakazato G, de Campos TA, Stehling EG, et al. Virulence factors of avian pathogenic Escherichia coli (APEC). Pesquisa Vet Brasil 2009;29:479-86.

55. Ozawa M, Baba K, Asai T. Molecular typing of avian pathogenic Escherichia coli 078 strains in Japan by using multilocus sequence typing and pulsed-field gel electrophoresis. J Vet Med Sci 2010;72:1517-20.
56. Poolman J, Wacker M. Extra-intestinal pathogenic Escherichia coli (ExPEC), a common human pathogen: challenges for vaccine development and progress in the field. J Infect Dis 2015 [In Press].

57. Quan J, Zhao D, Liu L, et al. High prevalence of ESBL- producing Escherichia coli and Klebsiella pneumoniae in community-onset bloodstream infections in China. J Antimicrob Chemother 2017;72:273-80.

58. Ron EZ. Distribution and evolution of virulence factors in septicemic Escherichia coli. Int j Med Microbiol 2010;300:367-70.

59. Saglam D, Erçal BD, Ya mur G, et al. Distribution of microorganisms isolated from blood cultures collected from the neonatal intensive care units of Kayseri Training and Research Hospital. Abant Med J 2015;4:255-60.

60. Schierack P, Walk N, Ewers C, et al. ExPEC-typical virulence-associated genes correlate with successful colonization by intestinal $\mathrm{E}$. coli in a small piglet group. Environ Microbiol 2008;10:1742-51.

61. Shaw RK, Cleary J, Murphy MS, et al. Interaction of enteropathogenic Escherichia coli with human intestinal mucosa: role of effector proteins in brush border remodeling and formation of attaching and effacing lesions. Infect Immun 2005;73:1243-51.

62. Tajbakhsh E, Ahmadi P, Abedpour-Dehkordi E, et al. Biofilm formation, antimicrobial susceptibility, serogroups and virulence genes of uropathogenic E. coli isolated from clinical samples in Iran. Antimicrob Resist Infect Control 2016;5:11.

63. Tanyel E, Fı gın NT, Genç S, Tülek N. Escherichia coli bakteriyemisi olan olguların de erlendirilmesi. Klimik Derg 2008;21:109-11.

64 Turhan EE, Gürsoy T, Ovalı F. Factors which affect mortality in neonatal sepsis. Turk Pediatr Assoc 2015:170-5.

65 Turunç V, Ero lu A, Cihandide E, et al. Escherichia Coli related necrotizing fasciitis after renal transplantation: a case report. Transplant Proc 2015:1518-21.

66. Walters MS, Lane MC, Vigil PD, et al. Kinetics of uropathogenic Escherichia coli metapopulation movement during urinary tract infection. mBio 2012;3.

67. Wijetunge DS, Gongati S, DebRoy C, et al. Characterizing the pathotype of neonatal meningitis causing Escherichia coli (NMEC). BMC Microbiol 2015;15:211.

68. Wiles TJ, Mulvey MA. The RTX pore-forming toxin alpha-hemolysin of uropathogenic Escherichia coli: progress and perspectives. Future Microbiol 2013;8:73-84.

69. Yetkin G, Kuzucu Ç, Çaı kan A, Ay S. Kan Kültürlerinde Üreyen Escherichia coli'lerin antibiyotik duyarlılıkları, GSBL oranları ve hastane birimlerine göre da ılımı. nönü Üniversitesi Tıp Fakültesi Derg 2006;13:147-50.

70. Yilmaz N, Agus N, Bayram A, et al. Antimicrobial susceptibilities of Escherichia coli isolates as agents of community-acquired urinary tract infection (2008-2014). Turk J Urol 2016;42:32-6.

71. Yilmaz NO, Agus N, Helvaci M, et al. Change in pathogens causing late-onset sepsis in neonatal intensive care unit in Izmir, Turkey. Iran J Pediatr 2010;20:451-8.

72. Yilmaz Y, Tekkanat Tazegun Z, Aydin E, Dulger M. Bacterial uropathogens causing urinary tract infection and their resistance patterns among children in Turkey. Iran Red Cresc Med J 2016;18:e26610.

73. Yumuk Z, Afacan G, Nicolas-Chanoine MH, et al. Turkey: a further country concerned by community-acquired Escherichia coli clone 025-ST131 producing CTX-M-15. J Antimicrob Chemother 2008;62:284-8.

74. Yurtsever SG, Çeken N, Payzın B, et al. M. Febril nötropenik hastalarin kan kültürlerinden izole edilen mikroorganizmalar ve antimikrobiyal duyarlilik profili. Nobel Med 2011;7:74-8. 